\title{
Comparison of the effects of intraoperative morphine, fentanyl or paracetamol administration on postoperative pain level and analgesic consumption in patients with synchronous intraoprative remifentanil infusion
}

\author{
Cigdem AKYOL BEYOGLU ${ }^{1}$ (D), Ercument YENTUR ${ }^{2}$ (D) \\ Department of Anesthesiology and Reanimation, Cerrahpasa School of Medicine,Istanbul University, Istanbul, Turkey. \\ 2 Department of Anesthesiology and Reanimation, School of Medicine, Istanbul Bilim University, Istanbul, Turkey.
}

Corresponding Author: Cigdem AKYOL BEYOGLU E-mail: akyolbeyoglu@gmail.com

Submitted: $04.11 .2019 \quad$ Accepted: 21.01.2020

\begin{abstract}
Objective: We aimed to compare the effects of morphine, fentanyl or paracetamol applied for anesthesia induction and at the end of the surgery for postoperative pain control and analgesic consumption in patients who have undergone pelvic and lower abdominal surgery.

Material and Methods: Patients with the American Society of Anesthesiologists (ASA) score I-II and aged between 18-70 years were given intravenous remifentanil intraoperatively. Fentanyl was administered in doses of $1.5 \mathrm{mcg} / \mathrm{kg}$ during anesthesia induction and $10 \mathrm{~min}$ before the end of the surgery. In fentanyl group, morphine was administered in doses of $0.1 \mathrm{mg} / \mathrm{kg}$ during induction and 0.5 $\mathrm{mg} / \mathrm{kg} 30 \mathrm{~min}$ before the end of the surgery and paracetamol was administered in doses of $10 \mathrm{mg} / \mathrm{kg}$ during induction and $5 \mathrm{mg} / \mathrm{kg}$ $30 \mathrm{~min}$ before the end of the surgery. Morphine was administered for patient-controlled analgesia.

Results: The mean verbal pain scores of the paracetamol group were significantly higher when compared to the pain scores of the other groups at the $0,1,2,3,4,8,12$, and 16 hours $(\mathrm{p}<0.01, \mathrm{p}=0.02)$. Postoperative morphine consumption in the paracetamol group was significantly higher $(\mathrm{p}=0.02)$.

Conclusion: The addition of intraoperative paracetamol to the remifentanil infusion, may not be sufficient in postoperative analgesia in gynecologic cancer surgery.

Keywords: Morphine, Paracetamol, Fentanyl, Postoperative pain.
\end{abstract}

\section{INTRODUCTION}

Postoperative pain is an acute form of pain that begins with surgical trauma and ends with tissue healing. In the postoperative period, many physiological responses including various systems develop with acute pain. In this respect, pain relief provides metabolic and endocrine stress response, reduction of thromboembolic complications, preservation of cognitive functions, shortening of mobilization and rehabilitation period, reduction of hospital stay and cost, and prevention of chronic pain.

Nowadays, opioids, non-opioids and local anesthetics are used in the treatment of postoperative pain. Opioids are the primary drugs used for this purpose. Systemic opioids should be used preoperatively, intraoperatively and postoperatively for effective postoperative analgesia management.

Remifentanil is a short-acting opioid. Intraoperative use of remifentanil has no effect on pain control in the postoperative period. Morphine is a strong, natural, $\mu$ receptor agonist opioid, commonly used in postoperative pain management. Fentanyl is a synthetic opioid with strong analgesic activity than morphine. Paracetamol inhibits prostaglandin synthesis via central cyclooxygenase (COX) inhibition in the central nervous system, and also shows analgesic activity by its indirect effects on serotoninergic system. It was introduced into clinical use in 2002 and has been shown to be effective in the treatment of postoperative pain in various clinical studies [1].

In our study, we aimed to compare the effects of morphine, fentanyl or paracetamol administered in addition to remifentanil infusion at anesthesia induction and postoperative use on pain control and analgesic consumption in the postoperative period on patients who have undergone pelvic and lower abdominal surgery with vertical incision due to gynecological cancer (endometrium or ovarian cancer).

How to cite this article: Akyol Beyoglu C, Yentur E. Comparison of the effects of intraoperative morphine, fentanyl or paracetamol administration on postoperative pain level and analgesic consumption in patients with synchronous intraoprative remifentanil infusion. Marmara Med J 2020;33: 102-106 doi: $10.5472 /$ marumj.748638 


\section{PATIENTS and METHODS}

The study was approved by the Istanbul University Cerrahpasa Ethics Committee (C-002) on 12 January 2010. Sixty patients aged between 18-70 years with the American Society of Anesthesiology (ASA) score I-II were included in the study. Informed consent was obtained from the patients. Patients with a history of alcohol and drug addiction, pregnant women and obese patients with a body mass index above $35 \mathrm{~kg} / \mathrm{m} 2$, suffering from chronic pain, who were undergoing revisional surgery and who had radiotherapy previously were excluded from the study.

After the patients were taken to the operating room, standardized monitoring was performed including heart rate (HR) and electrocardiography (ECG), non-invasive systolic blood pressure (NIBP), diastolic blood pressure (BP) and peripheral oxygen saturation (SpO2). Lactated ringer infusion was started at a rate of $4 \mathrm{ml} / \mathrm{h}$ by opening a $20 \mathrm{G}$ intravenous vascular access through the left hand. Sixty patients were randomly divided into 4 groups by closed envelope method. Midazolam $2 \mathrm{mg}$ was administered intravenously (iv) to the patients. During anesthesia induction $1 \mathrm{mcg} / \mathrm{kg}$ iv remifentanil in the remifentanil group (Group R), $1.5 \mathrm{mcg} / \mathrm{kg}$ iv fentanyl in the fentanyl group (Group F), $0.1 \mathrm{mg} / \mathrm{kg}$ morphine in the morphine group (Group M) and $10 \mathrm{mg} / \mathrm{kg}$ paracetamol in the paracetamol group (Group $P$ ) were administered. At the end of the surgery $1.5 \mathrm{mcg} / \mathrm{kg}$ fentanyl 10 minutes before surgical closure in Group $\mathrm{F}, 0.05 \mathrm{mg} / \mathrm{kg}$ morphine 30 minutes before surgical closure in Group M, $5 \mathrm{mg} / \mathrm{kg}$ paracetamol 30 minutes before surgical closure in Group P were administered as additional doses. All groups received iv remifentanil at the infusion rate of $0.1 \mathrm{mcg}$ / kg / min intraoperatively. Age, ASA score, weight, height and body mass index (BMI) of the patients and operation time were recorded.

During anesthesia induction, $2 \mathrm{mg} / \mathrm{kg}$ propofol was given to the patients and neuromuscular block was provided with $0.8 \mathrm{mg} / \mathrm{kg}$ rocuronium bromide and orotracheal intubation was performed. After tracheal intubation, anesthesia was maintained with 50\% 02-air mixture (0.5-1 MAK) with desflurane. Mechanical ventilation was performed with tidal volume $6-8 \mathrm{ml} / \mathrm{kg}$ and respiratory rate 10-14 / $\mathrm{min}$ (ETCO2 $35-40 \mathrm{~mm} \mathrm{Hg}$ ). Intermittent $10 \mathrm{mg}$ of rocuronium bromide was given as a bolus dose if needed to ensure neuromuscular block. Hypotension was evaluated as systolic arterial pressure $<80 \mathrm{~mm} \mathrm{Hg}$ or a decrease more than $20 \%$ at baseline value, and was treated with $5 \mathrm{ml} / \mathrm{kg}$ iv fluid infusion, $20 \%$ reduction in inhalation anesthesia, decrease of remifentanil infusion rate and $5 \mathrm{mg}$ ephedrine bolus administration respectively. Bradycardia was evaluated as heart rate $<50$ beats / min and corrected with $0.5 \mathrm{mg}$ atropine iv injection. Intraoperative tachycardia and hypertension were evaluated as superficial anesthesia after exclusion of other causes and iv $1 \mathrm{mcg} / \mathrm{kg}$ bolus remifentanil was administered.

In the postoperative period, patient controlled analgesia (PCA) method was prepared with $1 \mathrm{mg} / \mathrm{ml}$ morphine, and 1 mg PCA dose was administered with a lock time of 5 minutes.
Postoperatively, all patients were observed in the PostAnesthesia Care Unit (PACU) for 24 hours. A 4 h limit dose of $300 \mathrm{mcg} / \mathrm{kg}$ was applied to the patients during iv PCA usage.

In PACU, each patient's BP, HR, and SpO2 were recorded once per hour. Preoperative pain scale called verbal rating scale (VRS) numbered 0 to 4 was described to the patients [1]. This assessment was recorded once as soon as the patients were extubated and admitted to PACU, and at 1, 2, 3 and 4 hours after arriving PACU and every 4 hours thereafter. After admission to PACU, sedation levels were evaluated according to the number of alertness levels numbered from 1 to 5 [2]. This assessment was recorded once at the 1st, 2nd, 3rd and 4th hours in PACU and every 4 hours thereafter.

Nausea and vomiting were recorded during a 24-hour observation. Nausea and vomiting were treated with $4 \mathrm{mg}$ ondansetron iv. A 24-hour morphine consumption at PACU was recorded.

The primary endpoint of our study was the VRS ( 2 and below), and the secondary endpoint was postoperative morphine consumption.

\section{Statistical Analysis}

Statistical Package for Social Sciences (SPSS) for Windows 17.0 was used for statistical analysis. Descriptive statistical methods (Mean, Standard deviation, Frequency, Percent) as well as qualitative data were compared using the chi-square test.

In the comparison of quantitative data; One way ANOVA was used for the comparison of the parameters between the groups. Repeated Measures ANOVA was used for intragroup comparisons of the parameters. $\mathrm{P}<0.05$ was considered as statistically significant.

\section{RESULTS}

There was no significant difference between the groups in terms of age, weight, height and BMI (Table I).

Table I. Demographic data according to groups

\begin{tabular}{|l|l|l|l|l|l|}
\hline Groups & Group P & \multicolumn{1}{|c}{ Group M } & \multicolumn{1}{c|}{ Group F } & Group R & $p$ \\
\hline Age (year $\pm S S)^{*}$ & $47.5 \pm 10.1$ & $50.8 \pm 13.1$ & $49.2 \pm 13.3$ & $53.9 \pm 15.5$ & 0.6 \\
\hline BW(kg $\pm S S)^{*}$ & $70.8 \pm 10.2$ & $69.4 \pm 9.0$ & $70.2 \pm 14.4$ & $68,1 \pm 12.5$ & 0.9 \\
\hline Height $(\mathrm{cm} \pm S S) *$ & $160.2 \pm 6.9$ & $158.6 \pm 5.3$ & $159.1 \pm 7.4$ & $155.3 \pm 7.8$ & 0.2 \\
\hline BMI(kg/m² $\pm S S)^{*}$ & $29.2 \pm 4.9$ & $29.7 \pm 6.3$ & $28.0 \pm 6.2$ & $28.4 \pm 7.3$ & 0.9 \\
\hline
\end{tabular}

BW: Body weight, BMI: Body mass index

*: Data are presented as \pm standard deviation

The mean VRS was significantly higher in Group $P$ than in Group M, Group F and Group R at the 0, 1, 2, 3, 4, 8, 12, and $16 \mathrm{~h}$ measurements postoperatively ( $p<0.01, p=0.02)$. The difference between the groups in terms of VRS levels was not statistically significant at 20th and 24th hours $(p=0.21, p=$ 0.09) (Table II) (Figure1). 


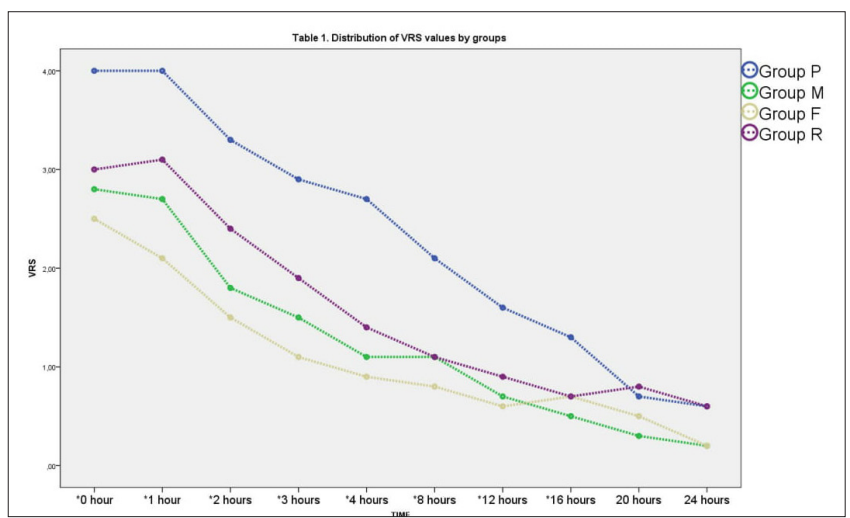

Figure1. Verbal rating scale scores according to groups/ Graph of verbal rating scale and timing

Table II. VRS scores according to groups

\begin{tabular}{|l|c|c|c|c|c|}
\hline VRS & Group P & Group M & Group F & Group R & $p$ \\
\hline $0 \mathrm{~h}$ & $4.0 \pm 0.0$ & $2.8 \pm 0.8$ & $2.5 \pm 0.8$ & $3.0 \pm 0.9$ & 0.00 \\
\hline 1th h & $4.0 \pm 0.0$ & $2.7 \pm 0.8$ & $2.1 \pm 0.9$ & $3.1 \pm 0.9$ & 0.00 \\
\hline 2.nd h & $3.3 \pm 0.9$ & $1.8 \pm 0.7$ & $1.5 \pm 0.9$ & $2.4 \pm 1.1$ & 0.00 \\
\hline 3.rd h & $2.9 \pm 0.6$ & $1.5 \pm 0.6$ & $1.1 \pm 0.6$ & $1.9 \pm 1.1$ & 0.00 \\
\hline 4.th h & $2.7 \pm 0.6$ & $1.1 \pm 0.6$ & $0.9 \pm 0.8$ & $1.4 \pm 0.9$ & 0.00 \\
\hline 8.th h & $2.1 \pm 0.5$ & $1.1 \pm 0.8$ & $0.8 \pm 0.7$ & $1.1 \pm 0.7$ & 0.00 \\
\hline 12.th h & $1.6 \pm 0.6$ & $0.7 \pm 0.5$ & $0.6 \pm 0.6$ & $0.9 \pm 0.7$ & 0.00 \\
\hline 16.th h & $1.3 \pm 0.0$ & $0.5 \pm 0.6$ & $0.7 \pm 0.8$ & $0.7 \pm 0.5$ & 0.02 \\
\hline 20.th h & $0.7 \pm 0.0$ & $0.3 \pm 0.7$ & $0.5 \pm 0.5$ & $0.8 \pm 0.8$ & 0.21 \\
\hline 24.th h & $0.6 \pm 0.8$ & $0.2 \pm 0.4$ & $0.2 \pm 0.4$ & $0.6 \pm 0.6$ & 0.09 \\
\hline
\end{tabular}

VRS: Verbal rating scale

Data are presented as \pm standart deviation

Postoperative morphine consumption levels of Group P were significantly higher than Group M and Group F ( $p=0.02$ ) (Table III).

Table III. Morphine consumption according to groups

\begin{tabular}{|l|c|c|c|c|c|}
\hline & Group P & Group M & Group F & Group R & $p$ \\
\hline $\begin{array}{l}\text { Morphine } \\
\text { consumption } \\
\text { (mg } \pm \text { SS)* }\end{array}$ & $45.9 \pm 12.6$ & $30.1 \pm 19.1$ & $29.7 \pm 20.8$ & $35.9 \pm 8.9$ & 0.02 \\
\hline
\end{tabular}

*: Data are presented as \pm standard deviation

Intraoperative remifentanil consumption was ( $\mathrm{mcg} / \mathrm{kg} / \mathrm{dk}) 0.14$ $( \pm 0.1), 0.12( \pm 0.5), 0.12( \pm 0.9), 0.12( \pm 0.5)$ in $P, M, F$ and $R$ groups respectively and this was statistically insignificant between groups ( $p>0.05)$.

There was no significant difference between the groups in terms of postoperative nausea and vomiting (Table IV).

The mean sedation score was significantly lower in Group $R$ than Group M, Group F, and Group P at the Oth hour ( $p<0.01)$. The mean sedation score was significantly lower in Group $P$ than Group M and Group F ( $p<0.01)$.
There was no statistically significant difference between the groups in terms of heart rates levels at the 1st, 2nd, 3rd, 4th, 8 th, 12th, 16th, 20th and 24th hour measurements ( $p>0.05$ ).

The mean arterial pressures between the groups were not statistically significant at the 1st, 2nd, 3rd, 4th, 8th, 12th, 16th, 20th and 24th hour measurements ( $p>0.05)$.

There was no significant difference between the groups in terms of operation and anesthesia time ( $p>0.05)$.

\section{DISCUSSION}

Acute postoperative pain is still a research area among anesthesiologists. Effective postoperative analgesia leads to a reduction in morbidity and hospitalization time due to stress and anxiety. In studies on postoperative analgesia, opioids are used as the main drug of perioperative analgesia. In our study, the mean VRS of patients in Group P was significantly higher compared to Group M, Group F and Group R. In our study, VRS score was 2 or less in Group F patients at the 1st hour and after, and postoperative morphine consumption was similar between Group F and Group M patients.

Previous studies have shown that intraoperative use of fentanyl provides effective postoperative analgesia [3]. In Kochs et al. study, 553 patients who underwent elective major abdominal surgery were given $150 \mathrm{mcg}$ fentanyl or $15 \mathrm{mg}$ morphine 20 minutes before the end of the surgery and they had a sufficient analgesia [4]. The results of our study show similarity with the studies comparing the efficacy of morphine and fentanyl on postoperative pain level. In our study, no significant difference was found between postoperative VRS scores in patients receiving intraoperative morphine or fentanyl.

Claxton et al. used morphine and fentanyl for postoperative analgesia in daily surgical procedures; and reported that the use of morphine and fentanyl for acute postoperative pain treatment in PACU after surgery provided an equivalent level of analgesia, and visual analogue scale scores were higher in the fentanyl group in patients who were referred to the ward after 50 minutes [5]. In addition, patients in the fentanyl group used a higher dose of oral analgesics in the surgical ward. This is a predictable outcome given for the duration of action of fentanyl and morphine. In our study, the difference between postoperative VRS scores in the morphine and fentanyl groups was not statistically significant. The patients in Group $F$ had a VRS score of 2 or less at the postoperative 2 nd hour and after, similar to Group M. In our study, we applied postoperative iv morphine PCA for postoperative pain treatment to both groups. Postoperative morphine consumption was similar in both groups. Therefore, in our study, we think that VRS level in Group $\mathrm{F}$ lasts as long as Group $\mathrm{M}$, which may be due to morphine use in the postoperative period.

Paracetamol is a non-opioid analgesic with a low incidence of side effects and drug interaction. There are less adverse effects such as platelet dysfunction, nephrotoxicity, gastrointestinal side effects, agranulocytosis and sodium retention compared to NSAIDs. Hepatotoxicity and hepatic insufficiency, which are 
the most important side effects, are not observed unless the recommended doses are exceeded [6]. Previous studies have shown that although opioid is used for induction of anesthesia, paracetamol including abdominal surgery, can provide effective postoperative analgesia in patients undergoing abdominal surgery. In most of these studies, paracetamol was compared to NSAID drugs [7-10]. Some clinical studies have shown that intravenous paracetamol may provide postoperative analgesia similar to morphine and is tolerated more easily [1113]. These results are not consistent with our study. In these studies, paracetamol was administered as proparacetamol and administered at a dose of $2 \mathrm{~g}$ iv [11-13]. Van Aken et al., concluded that the reason for the equivalent effect of paracetamol and morphine in the treatment of postoperative pain was due to the low number of patients and the insuciffiency of the power of in their study [12]. In our study, we did not give opioids to patients in Group P intraoperatively except for remifentanil infusion. We also compared paracetamol with opioids with strong analgesic activity and applied these opioids in the pre-extubation period in addition to anesthesia induction. As a result of our study, we believe that paracetamol may be insufficient to provide effective postoperative analgesia in patients undergoing lower abdominal and pelvic surgery without additional opioid analgesia. However, in the current study patients in Group P had higher VRS scores and morphine consumption compared to Group R. In a previous study, intraoperative remifentanil infusion was found as effective as fentanyl administration and authors declared that remifentanil had any hyperalgesic effect [2]. In the same study, it was presented that remifentanil may have an analgesic effect up to 60 minutes [2]. In addition, another study comparing the analgesic effects of remifentanil and paracetamol, pain scores did not differ significantly between groups [14]. Remifentanil has a more stronger analgesic effect compared to morphine [14]. In accordance with previous studies, Group R provided a sufficient analgesia in our study. We divided an effective paracetamol dose into two; one dose during anesthesia induction another dose at the end of the surgery. We think that the reason why paracetamol was not as effective as remifentanil in our study may be due to the use of a higher dose at the beginning of the surgery. However, the analgesic effect of dividing paracetamol into two doses should be researched in further studies.

Opioids are known to cause nausea and vomiting [4, 8, 15-17]. In our study, we did not find a significant difference between the groups in terms of nausea and vomiting rates. We think that this may be due to insufficient number of patients included in the study.

One limitation of our study was that paracetamol was used only intraoperatively. This may cause a confusion evaluating the effect of paracetamol on postoperative pain treatment. Postoperative analgesic effects of opioids used in the study have long-term effects. However, the routine dose of paracetamol in postoperative pain treatment is administered at 4-6 hour intervals [18].

In the first 16 hours, VRS values were found to be significantly higher in patients receiving paracetamol in addition to remifentanil infusion to provide postoperative analgesia in gynecologic cancer surgery.

As a conclusion; postoperative morphine consumption was significantly higher in patients receiving paracetamol for postoperative pain treatment compared to fentanyl and morphine groups.

In the postoperative period, no complications developed related to the drugs used intraoperatively.

We suggest that intraoperative paracetamol used in addition to remifentanil infusion in gynecologic cancer surgery may not be sufficient to provide postoperative analgesia.

We believe that this issue should be investigated in prospective, clinical, randomized studies in the future.

\section{Compliance with Ethical Standards}

Ethical Approval: This study was approved by Istanbul University Cerrahpasa Ethics Committee (C-002) on 12 January 2010.

Funding: None

Conflict of Interest: The authors declare that they have no conflict of interest.

Informed Consent: A written informed consent was obtained from each participant.

Authors' Contributions: C A B: contributed to the conception, design of the work, the acquistion, analysis of data, interpretation of data for the work, drafting the work or revising it critically for important intellectual content, and final approval of the version to be published.

E Y: contributed to the conception, design of the work, the acquistion, analysis of data, interpretation of data for the work, revising it critically for important intellectual content, and final approval of the version to be published.

\section{REFERENCES}

[1] Flouvat B, Leneveu A, Fitoussi S, Delhotal-Landes B, Gendron A. Bioequivalence study comparing a new paracetamol solution for injection and propacetamol after single intravenous infusion in healthy subjects. Int J Clin Pharmacol Ther 2004;42:50-7. doi:10.5414/cpp42050

[2] Lenz H. Raeder J, Hoymork SC. Administration of fentanyl before remifentanil-based anaesthesia has no influence on post-operative pain or analgesic consumption. Acta AnaesthesiolScand 2008; 52: 149-54. doi: 10.1111/j.13996576.2007.01471.x

[3] Motamed C, Merle JC, Yakhou L, et al. Postoperative pain scores and analgesic requirements after thyroid surgery: Comparison of three intraoperative opioid regimens. Int J Med Sci 2006;3:11-3. doi:10.7150/ijms.3.11

[4] Kochs E, Cote D, Deruyck L, et al. Postoperative pain management and recovery after remifentanil-based anesthesia with isoflurane or propofol for major abdominal surgery. Br J Anaesth 2000; 84:169-73. doi:10.1093/ oxfordjournals.bja.a013398 
[5] Claxton RA, McGuire G, Chung F, Cruise C. Evaluation of morphine versus fentanyl for postoperative analgesia after ambulatory surgical procedures. Anesth Analg 1997; 84:50914.

[6] Benson GD. Acetaminophen in chronic liver disease. Clin Pharmacol Ther 1983;33: 95-101. doi: 10.1038/clpt.1983.14

[7] Toygar P, Akkaya T, Özkan D, Özel Ö, Uslu E, Gümüş H. Lomber diskektomi operasyonlarında i.v. parasetamolün preemptif analjezik etkisi var mı? Ağrı 2008;20:14-9.

[8] Arıcı S, Gurbet A, Türker G. Preemptive analgesic effects of intravenous paracetamol in total abdominal hysterectomy. Ağrı 2009;21:54-61.

[9] Jirarattanaphochai K, Jung S. Nonsteroidal anti-inflammatory drugs for postoperative pain management after lumbar spine surgery: a meta-analysis of randomized controlledtrials. J Neurosurg Spine 2008;9:22-31. doi: 10.3171/ SPI/2008/9/7/022.

[10] Korkmaz DÖ, Tunalı Y, Cakmakkaya SÖ, et al. Efficacy of intravenous paracetamol, metamizol and lornoxicam on postoperative pain and morphine consumption after lumbar disc surgery. Eur J Anaesthesiol 2010; 27:428-32. doi:10.1097/ EJA.0b013e32833731a4.

[11] Zhou TJ, Tang J, White PF. Propacetamol versus ketorolac for treatment of acute postoperative pain after total hip or knee replacement. Aneth Analg 2001;92:1569-75.

[12] Van Aken H, Thys L, Veekman L, Buerkle H. Assessing analgesia in single and repeated administrations of propacetamol for postoperative pain: comparison with morphine after dental surgery. Anesth Analg 2004;98:159-65.

[13] Varrasi G, Marinangeli F, Agro F, et al. A double-blinded evaluation of propacetamol versus ketorolac in combination with patient-controlled analgesia morphine: analgesic efficacy and tolerability after gynecologic surgery. Anesth Analg 1999;88:611-6.

[14] Fard AJ, Babaee T, Alavi SM, et al. Intravenous patientcontrolled remifentanil versus paracetamol in post-operative pain management in patients undergoing coronary artery bypass graft surgery. Anesth Pain Med 2014 December; 4(5): e19862.

[15] Claxton AR, McGuire G, Chung F, Cruise C. Evaluation of morphine versus fentanyl for postoperative analgesia after ambulatory surgical procedures. Anesth Analg 1997;84:50914.

[16] Twersky SR, Jamerson B, Warner SD. Hemodynamics and emergence profile of remifentanil versus fentanyl prospectively compared in a large population of surgical patients. Journal of clinical anesthesia 2000;13:407-16.

[17] Bowdle A T, Camprosei ME, Maysick L. A multicenter evaluation of remifentanil for early postoperative analgesia. Anesth Analg 1996;83:1292-7.

[18] Huang PS, Gleason SM, Shah JA, Buros AF, Hoffman DA. Efficacy of intravenous acetaminophen for postoperative analgesia in primary total knee arthroplasty. J Arthroplasty 2018;33:1052-6. doi: 10.1016/j.arth.2017.10.054. 